\title{
The Influence of Magnetohydrodynamic Power on the Deposition of Silver Dendrites on the Titanium Surface after Anodic Oxidation
}

\author{
Jeremiasz Krzysztof Koper \\ Institute of Materials Science and Engineering, Poznan University of Technology, Plac Marii \\ Sklodowskiej-Curie 5, 60-965 Poznan \\ E-mail: jeremiasz.koper@put.poznan.pl
}

doi: $10.20964 / 2018.01 .89$

Received: 11 October 2017 / Accepted: 7 November 2017 / Published: 16 December 2017

\begin{abstract}
The publication presents the influence of an external magnetic field of $1.2 \mathrm{~T}$ on the process of silver deposition. The external magnetic field interacted perpendicularly to the sample surface during the deposition process. The surface of the titanium sample was pre-modified by anodic oxidation. Such a surface modification causes the deposited silver to take the form of dendrites. As a result of the influence of the magnetic field, the silver dendrites were shortened and the size of their crystallites was reduced. Changes have also been reported at the nucleation stage during the deposition process. The negative magnetic field accelerated the process, causing the deposited silver particles to become thinner. The positive magnetic field slowed down the process, causing the deposited silver particles to become thicker. By modifying the magnetic field, the morphology of the deposited silver particles can be changed.
\end{abstract}

Keywords: Magnetohydrodynamic deposition, silver nanoparticles, titanium, anodic oxidation

\section{$\underline{\text { FULL TEXT }}$}

(C) 2018 The Authors. Published by ESG (www.electrochemsci.org). This article is an open access article distributed under the terms and conditions of the Creative Commons Attribution license (http://creativecommons.org/licenses/by/4.0/). 